\title{
Habitat use and movement patterns in the endangered ground beetle species, Carabus olympiae (Coleoptera: Carabidae)
}

\author{
Matteo NEGRO ${ }^{1}$, Achille CASALE ${ }^{2}$, Luca Migliore ${ }^{1}$, Claudia PALESTRINI ${ }^{1}$ and Antonio ROLANDO ${ }^{1}$ \\ ${ }^{1}$ Dipartimento di Biologia Animale e dell’Uomo, Università degli studi di Torino, via Accademia Albertina 13, 10123 Torino, Italy; \\ e-mail: matteo.negro@unito.it \\ ${ }^{2}$ Dipartimento di Zoologia e Genetica Evoluzionistica, Università degli studi di Sassari, via Muroni 25, 07100 Sassari, Italy
}

Keywords. Conservation biology, endemic species, habitat use, pitfall trapping, radio-tracking

\begin{abstract}
One of the most compelling challenges for conservation biologists is the preservation of species with restricted ranges. Carabus olympiae Sella, 1855, a ground beetle species inhabiting two small areas in the western Italian Alps, is an example of a steno-endemic and endangered insect species. Despite the fact that this species is historically well known to professional and amateur entomologists, its autecology is virtually unknown. In the present study we used pitfall traps to study habitat selection and phenology, and radiotelemetry to measure differences in movement parameters between sexes, habitats and periods. Data from pitfall trapping suggested that $C$. olympiae actively selects both shrubberies (alpen rose Rhododendron ferrugineum and bilberry Vaccinium myrtillus) and beech forests and avoids pastures, and that population size peaks in July. All radio-tagged individuals $(n=21)$ moved without a preferred direction, and were more active at night than by day. Males covered greater distances and had more tortuous trajectories than females. Distances covered in forests and alpen rose shrubberies were not significantly different, but paths in beech forests were more convoluted than in shrubberies. The movement pattern observed fits the requirements of a typical "olfactorytactile" insect predator that looks for prey by systematically exploring its territory. Movement parameters suggested that both beech forests and alpen rose shrubberies are suitable for this species and indicated that the spatial distribution of shrubs in shrubberies can constrain trajectories. The implications for conservation are: (i) any human intervention which results in enlargement of the present coverage of pastures should be controlled; (ii) forest management may be tolerated, with the condition that alpen rose shrubberies remain or develop after tree-cutting; (iii) once a shrubbery has established, it should be preserved through appropriate managem ent.
\end{abstract}

\section{INTRODUCTION}

One of the most compelling challenges for conservation biologists is the preservation of species with small or very small ranges of distribution (Collins \& Thomas, 1991; Arita et al., 1997; Gerlach \& Canning, 2001).

Among insects, the ground beetles (Coleoptera: Carabidae) include many species with more or less restricted ranges. This is particularly evident in the socalled hotspots of biodiversity, like the Alps, where some ancient lineages of carabids survived in Pleistocene refugia. About 800 ground beetle species are known so far in the Alps, 220 of which are endemic to the Southern (Italian) side of the chain (Casale \& Vigna Taglianti, 2005). Most of these are steno-endemic species (some belonging to endemic genera) localised in a few massifs, caves, or forest areas.

When species are localized to a few, small areas, the first, basic pre-requisite for their management and conservation is the knowledge of their autecology.

Carabus (Chrysocarabus) olympiae Sella, 1855 (Coleoptera: Carabidae) is a steno-endemic species known so far from two sites (a few hectares each) of the western Italian Alps. Because of this very restricted distribution and of an alarming population decline suffered in the years 1930-1942 (Malausa et al., 1983), C. olympiae is considered a priority species (i.e., a species for the conservation of which the European Community has particular responsibility), listed in the Annexes II and IV of the Habitat Directive (92/43/EEC). This species is also protected by international conventions such as Bern and Washington (CITES).

Despite $C$. olympiae being the object of older and more recent researches (Sturani, 1947; Mossakowski, 1979; Sota \& Ishikawa, 2004), many aspects of its ecology are still unknown. Hence, the main aim of the present study was to clarify some autecological habits (namely habitat use and movement patterns) that may be relevant to the conservation of this species. Habitat use and movements were studied using pitfall trapping and radiotelemetry methods.

\section{MATERIAL AND METHODS}

\section{Study area}

Research was carried out in the Sessera Valley $\left(45^{\circ} 40^{\prime} 16^{\prime \prime} \mathrm{N}\right.$; $8^{\circ} 05^{\prime} 07^{\prime \prime} \mathrm{E}$, Biella province, Piedmont, north western Italy), which is the type locality of the steno-endemic species Carabus olympiae Sella, 1855. The landscape of the study site (about 37 ha, confined between 1350 and $1450 \mathrm{~m}$ a.s.l.) is characterised mainly by beech Fagus sylvatica forests (i.e., the LuzuloFagetum phytosociological association). Small patches are also covered by shrubberies (alpen rose Rhododendron ferrugineum and bilberry Vaccinium myrtillus) and pastures (dominated by graminaceous plants).

The site, confined within a private protected area (Oasi Zegna), has been recently classified as Site of Community Importance (SCI), with the main conservation aim of protecting C. olympiae. 

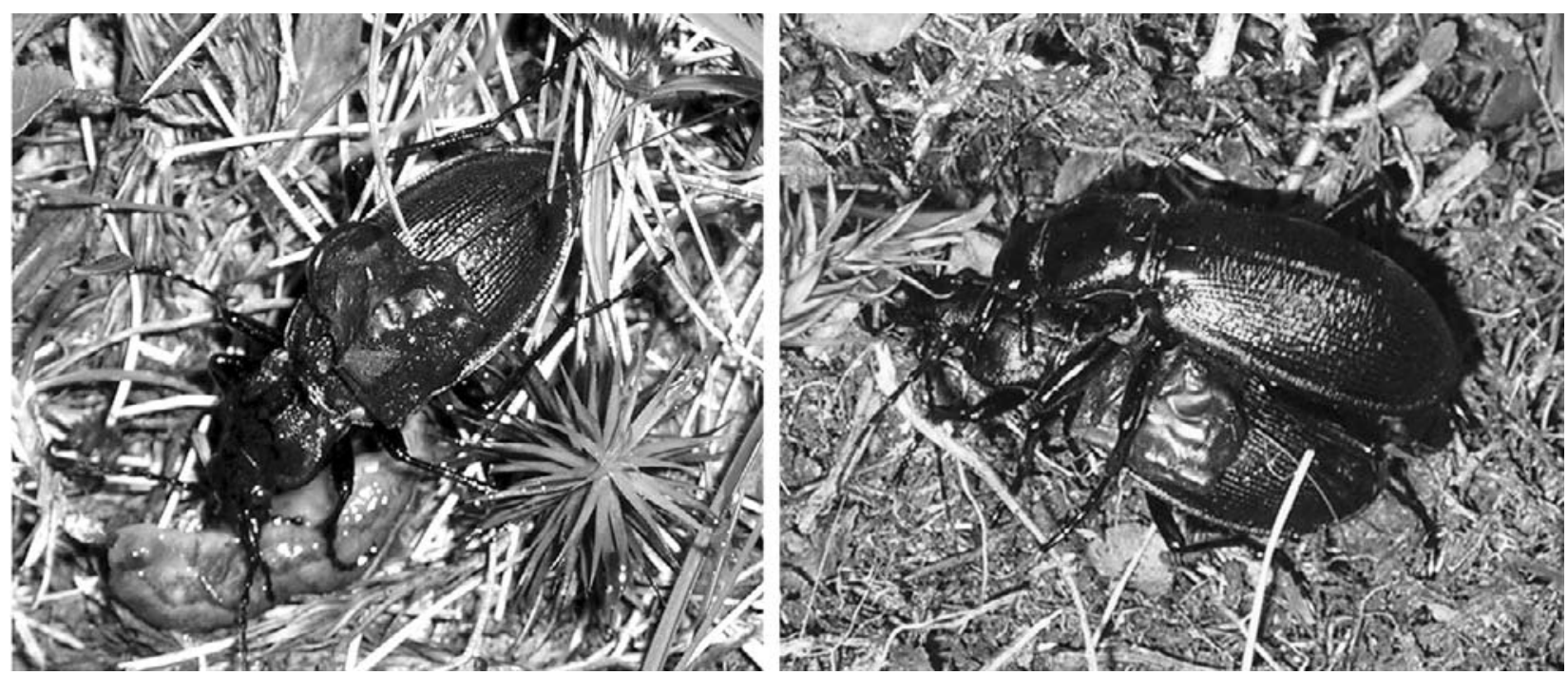

Fig. 1. A Carabus olympiae tagged male while preying on a slug (on the left) and a radio-tracked female during mating with an untagged partner (on the right).

Despite the great conservation relevance of the area, in the last fifty years the impact of human activities has increased, mainly due to the development of a winter sport resort. The construction of ski-runs and ski-pistes has severely changed the landscape.

\section{Field methods}

\section{Pitfall trapping}

Pitfall trapping is one of the oldest, lowest cost and simplest of all invertebrate sampling techniques, which has been widely used to obtain information on the effects of urbanisation (Niemelä et al., 2002) and habitat change (Assmann \& Janssen, 1999; Magura et al., 2001), life cycle (Khobrakova \& Sharova, 2005) and habitat selection (Niemelä et al., 1992; Negro et al., 2007) on invertebrate abundance and diversity. Carabid beetles are usually sampled using pitfall traps with killing and preservative agents. However, this sampling method may exert negative effects on the population size of rare and/or endangered species. Therefore, considering the high conservation importance of $C$. olympiae, we chose a capture-and-release approach, using traps with no killing and preservative agents to keep animals alive.

Traps used in this study derived from plastic bottles that had been cut in two parts, one cylindrical and one conical, the later re-inserted upside down into the former. Technically, they consisted of a polypropylene cylindrical container, $8 \mathrm{~cm}$ diameter and $15 \mathrm{~cm}$ deep, in which a conical cup with the same diameter, $10 \mathrm{~cm}$ deep, was inserted, the perforated bottom $(4 \mathrm{~cm}$ diameter $)$ downward. The cylindrical cup was filled with vinegar as attractant $(6 \mathrm{~cm}$ deep), the conical one with gravel to form a $2 \mathrm{~cm}$ thick bed whose inferior part was partly immersed in the vinegar below. No funnel was used because this species, like other carabid species endemic to the same area, are brachypterous, with short inefficient wings, and therefore unable to escape. Traps were covered by plastic rain shields to prevent flooding. Using this device, ground beetles which were caught stayed alive.

Pitfall-traps were used to study habitat selection (in 2004 and 2005) and individual movements (in 2005 and 2006). Elytrae were micro-abraded with a small file in order to mark individuals.

A total of 267 pitfall-traps were positioned in the three main habitats (beech forests, shrubberies and pastures): 117 in 2004 (32 in beech forest, 46 in alpen rose shrubbery and 39 in pasture), 120 in 2005 (32, 54, 34 respectively) and only 30 in 2006 (15 in forest and 15 in shrubbery). The exact location of traps was determined by means of a Global Positioning System (GPS) Garmin eTrex ${ }^{\circledR}$ Navigator. Traps were emptied at four-day intervals between 15 May and 30 September in 2004 and 2005.

\section{Radiotracking}

Several methods have been used to study the vagility of ground-dwelling insects: radio-active marking (Baars, 1979), chemical light-tags (Beaudoin-Ollivier et al., 2003), metal detector (Piper \& Compton, 2002), harmonic radar (Lövei et al., 1997, O’Neal et al., 2004) and radiotelemetry (Riecken \& Raths, 1996; Lorch et al., 2005).

Micro-tags were used for the first time by Riecken \& Raths (1996) to evaluate dispersal and habitat use of the common species Carabus coriaceus, the largest ground beetle occurring in Western Germany (body length $30-40 \mathrm{~mm}$ ). Later, the technique was refined further on by studying the dispersal power of the scarabaeid beetle Osmoderma eremita (Hedin \& Ranius, 2002), a threatened species living in hollow trees. Radiotelemetry was also used in agriculture-oriented surveys to study the flight movements of the coconut trees pest Scapanes australis australis (Coleoptera: Scarabaeidae: Dynastinae) (Beaudoin-Ollivier et al., 2003) and to reveal differences in individual movements between outbreak and non-outbreak populations in the generalist pest Anabrus simplex (Orthoptera: Ensifera: Tettigoniidae) (Lorch et al., 2005).

We used Micro-Pip transmitters (about $0.3 \mathrm{~g}, 15 \times 5 \times 4 \mathrm{~mm}$ ) developed by Biotrack Ltd, (Wareham, England, www.biotrack.co.uk) with specific individual frequencies. Individuals were radiotracked in July in 2005 and 2006. Tags were fixed on the top of the elytrae by means of cyanoacrylate glue, with the short antenna $(2.5 \mathrm{~cm})$ directed backwards (Fig. 1). Preliminary laboratory surveys showed that this substance was much better than the silicone glue used by Riecken \& Raths (1996). After radio-tagging, individuals were kept for some hours in a dark box before releasing them back to the wild. Radio-signals could be detected from about $300 \mathrm{~m}$. Under field conditions the longest tag battery life span was three weeks.

Tagged carabids were relocated twice a day, in early morning and at sunset, using a receiver and a hand-held Yagi directional antenna. The exact location was determined in the field by a 


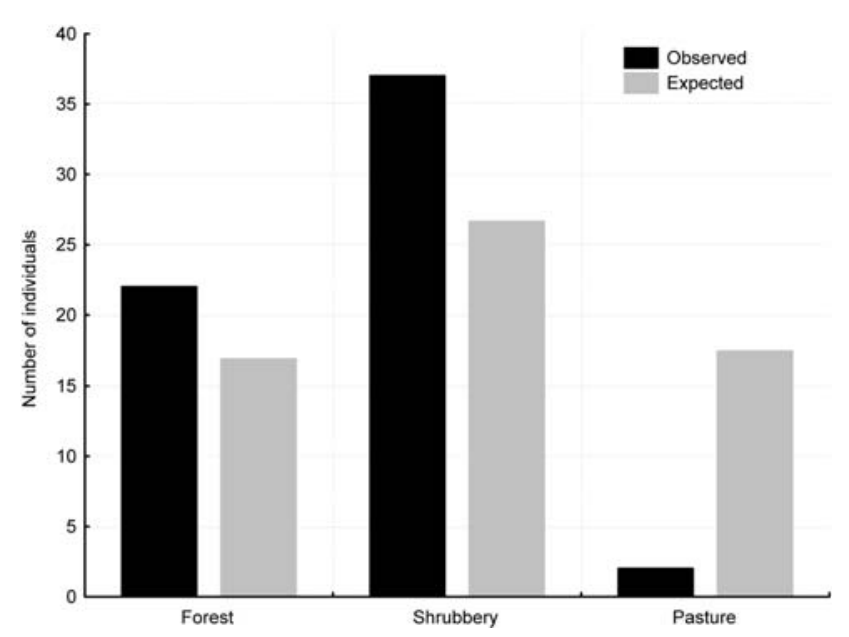

Fig. 2. Number of individuals observed and expected in each habitat (forest, shrubbery and pasture). Differences were significant $\left(\chi^{2}=19.25\right.$; d.f. $\left.=2 ; P<0.001\right)$. The total number of individuals caught was 61 .

GPS; a coloured peg was also driven into the soil, to avoid potential GPS measurement errors.

At the end of the experiment period, radio tagged individuals were caught to retrieve transmitters; afterward they were released.

\section{Data analysis}

Habitat use

Habitat use was evaluated by comparing the observed number of individuals trapped in each habitat type with the expected number, which on the assumption of no preference among habitats, was proportional to the sampling effort for each habitat (i.e., $\sum_{i}^{n} t_{i}$ where $t_{i}$ is the number of active traps per sampling day and $n$ the total number of sampling days).

\section{Movements}

Movements were studied by measuring the linear distances (with a telemeter) and the turning angles between consecutive fixes (Cain, 1989).

For each individual, independence among successive angles was tested by the non-parametric Runs Test called above and below the median, which is used to test the random sequence of a series of observations (turning angles, in our case) (Sokal \& Rohlf, 1995). To approach normality (checked by using normal probability plots), distance data were square-root transformed (Sokal \& Rohlf, 1995).

A good method to test the agreement among turning angles is the computation of angular concordance, or angular concentration (Zar, 1999; Fortin \& Dale, 2005). For any sets of data the angles $\left(\theta_{\mathrm{i}}\right)$ are represented in a circular system by vectors of unit length and coordinates $\left(x_{i}, y_{i}\right)$ by means of the following equations: $x_{i}=\cos \left(\theta_{\mathrm{i}}\right)$ and $y_{i}=\sin \left(\theta_{\mathrm{i}}\right)$. The coordinates of the mean vector are $(\bar{x}, \bar{y})$, while its length is equal to $r_{a}=\sqrt{\frac{-2}{x}+\frac{-2}{y}}$. The circular equivalent of the standard deviation is $\mathrm{s}=\sqrt{2\left(1-r_{a}\right)}$, which can be converted to degrees by multiplying by $180^{\circ} / \pi$ (Batschelet, 1981). The mean vector length $\left(r_{a}\right)$ takes value 1 when all the angles are the same and value 0 when the vectors cancel each other out (Upton \& Fingleton, 1989; Fortin \& Dale, 2005)

To check the compactness of the paths for each radio-tagged individual we calculated the Index of Tortuosity (T) that considers both distances and angles. This index is based on the

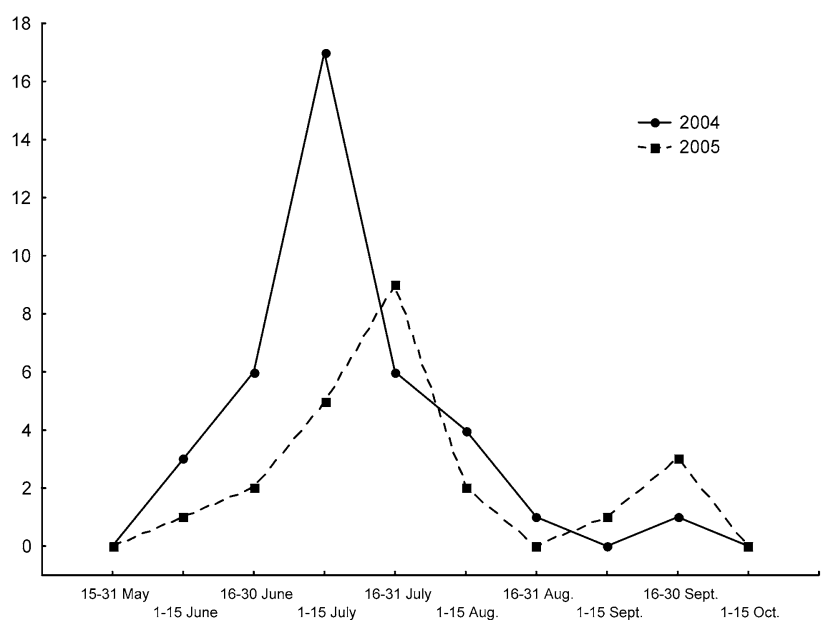

Fig. 3. Number of Carabus olympiae caught from May to October in 2004 and $2005(n=61)$. Individuals trapped in September, with the exception of one adult male, were third-instar larvae. Data are distributed over 15-day periods.

convex hull, which is the smallest convex polygon that contains the path. $\mathrm{T}$ is equal to the $\mathrm{L} / \mathrm{M}$ ratio, where $\mathrm{L}$ is the total distance covered, whereas $\mathrm{M}$ is the major diameter of the convex hull (Claussen et al., 1997).

Differences in vagility were tested by three-way ANOVA, considering habitat (beech forest and alpen rose shrubbery), period of the day (night and day) and sex as factors. Moreover, we applied a two-way ANOVA (habitat and sex as factors) to test variations in angular concordance and tortuosity.

\section{RESULTS}

\section{Habitat use and phenology}

The distribution of catches suggests that $C$. olympiae actively selects beech forests and alpen rose shrubberies, which accounted for 46.4 and $49.5 \%$ of the captures $(n=$ 61), respectively (Fig. 2). Differences between the observed number of individuals trapped in the three habitat types and the expected number were significant $\left(\chi^{2}=19.25\right.$; d.f. $\left.=2 ; P<0.001\right)$. Moreover, individuals caught in pastures (two, corresponding to $4.1 \%$ of the captures) were in the proximity of shrubs, not in full open habitat.

The activity period was mainly concentrated between the spring and the summer, peaking in July (Fig. 3). Some third-instar larvae were trapped toward the end of September in both trapping years.

\section{Movement patterns}

A total of 21 individuals of Carabus olympiae were captured by means of pitfall traps and subsequently radiomarked. They were released in the same place where they had been caught, nine (six males and three females) in the beech forest, twelve (seven males and five females) in the alpen rose shrubbery, and radio-tracked for a period comprised from one to three weeks, depending on the tag battery life span (see Table 1). A total of 527 fixes (250 in the forest and 277 in the shrubbery) were collected. All fixes collected in the beech forest regarded animals occurring under the leaf litter, whereas $90 \%$ of fixes col- 
TABLE 1. Mean \pm SD and maximum distances (in $\mathrm{m}$ ) covered by radio-tagged beetles by day and at night. Total = total distances covered by each individual. Individuals $1-6$ were radiotracked in 2005, 7-21 in 2006.

\begin{tabular}{|c|c|c|c|c|c|c|c|c|}
\hline \multirow{2}{*}{ No. } & \multirow{2}{*}{ Habitat } & \multirow{2}{*}{ Sex } & \multicolumn{2}{|c|}{ Mean } & \multicolumn{2}{|c|}{ Max } & \multirow{2}{*}{ Total } & \multirow{2}{*}{ Fix No. } \\
\hline & & & Day & Night & Day & Night & & \\
\hline 1 & forest & $\mathrm{f}$ & $0.2 \pm 0.3$ & $1.3 \pm 1.6$ & 0.5 & 3.4 & 12.2 & 16 \\
\hline 2 & shrubbery & $\mathrm{f}$ & $1.1 \pm 0.9$ & $4.0 \pm 3.3$ & 3.0 & 10.4 & 40.9 & 16 \\
\hline 3 & shrubbery & $\mathrm{f}$ & $0.2 \pm 0.3$ & $1.2 \pm 2.3$ & 1.0 & 9.0 & 24.8 & 30 \\
\hline 4 & shrubbery & $\mathrm{f}$ & $0.2 \pm 0.6$ & $3.3 \pm 3.4$ & 1.7 & 8.7 & 27.8 & 17 \\
\hline 5 & shrubbery & $\mathrm{m}$ & $0.4 \pm 0.4$ & $3.7 \pm 3.9$ & 1.2 & 11.8 & 33.0 & 16 \\
\hline 6 & shrubbery & $\mathrm{m}$ & $0.2 \pm 0.2$ & $5.5 \pm 3.7$ & 0.6 & 12.5 & 85.2 & 30 \\
\hline 7 & forest & $\mathrm{f}$ & $0.4 \pm 0.6$ & $2.1 \pm 1.5$ & 1.4 & 4.3 & 12.4 & 10 \\
\hline 8 & forest & $\mathrm{f}$ & $0.6 \pm 1.4$ & $4.8 \pm 5.2$ & 4.9 & 20.0 & 97.8 & 38 \\
\hline 9 & forest & $\mathrm{m}$ & $1.8 \pm 4.4$ & $16.7 \pm 13.2$ & 13.4 & 43.0 & 277.5 & 31 \\
\hline 10 & forest & $\mathrm{m}$ & $2.7 \pm 4.2$ & $3.2 \pm 2.9$ & 8.5 & 8.7 & 44.4 & 16 \\
\hline 11 & forest & $\mathrm{m}$ & $1.5 \pm 3.6$ & $17.0 \pm 14.7$ & 14.0 & 47.5 & 335.1 & 38 \\
\hline 12 & forest & $\mathrm{m}$ & $0.7 \pm 1.1$ & $5.6 \pm 4.8$ & 3.9 & 20.0 & 115.2 & 38 \\
\hline 13 & forest & $\mathrm{m}$ & $0.5 \pm 1.1$ & $19.5 \pm 17.6$ & 3.6 & 67.7 & 361.5 & 38 \\
\hline 14 & forest & $\mathrm{m}$ & $0.2 \pm 0.5$ & $3.4 \pm 5.5$ & 1.4 & 20.0 & 44.2 & 25 \\
\hline 15 & shrubbery & $\mathrm{f}$ & $0.9 \pm 1.7$ & $4.6 \pm 5.1$ & 4.2 & 14.0 & 32.7 & 12 \\
\hline 16 & shrubbery & $\mathrm{f}$ & $2.0 \pm 3.4$ & $8.1 \pm 9.1$ & 10.5 & 27.0 & 93.5 & 20 \\
\hline 17 & shrubbery & $\mathrm{m}$ & $1.7 \pm 3.3$ & $3.1 \pm 2.6$ & 8.4 & 7.0 & 28.6 & 13 \\
\hline 18 & shrubbery & $\mathrm{m}$ & $5.7 \pm 7.8$ & $13.8 \pm 13.8$ & 30.1 & 43.1 & 370.6 & 39 \\
\hline 19 & shrubbery & $\mathrm{m}$ & $1.0 \pm 2.2$ & $28.7 \pm 20.5$ & 7.0 & 77.7 & 564.8 & 39 \\
\hline 20 & shrubbery & $\mathrm{m}$ & $0.1 \pm 0.3$ & $3.1 \pm 6.7$ & 0.9 & 22.0 & 32.3 & 21 \\
\hline 21 & shrubbery & $\mathrm{m}$ & $0.4 \pm 0.5$ & $5.0 \pm 7.0$ & 1.5 & 23.0 & 65.4 & 24 \\
\hline
\end{tabular}

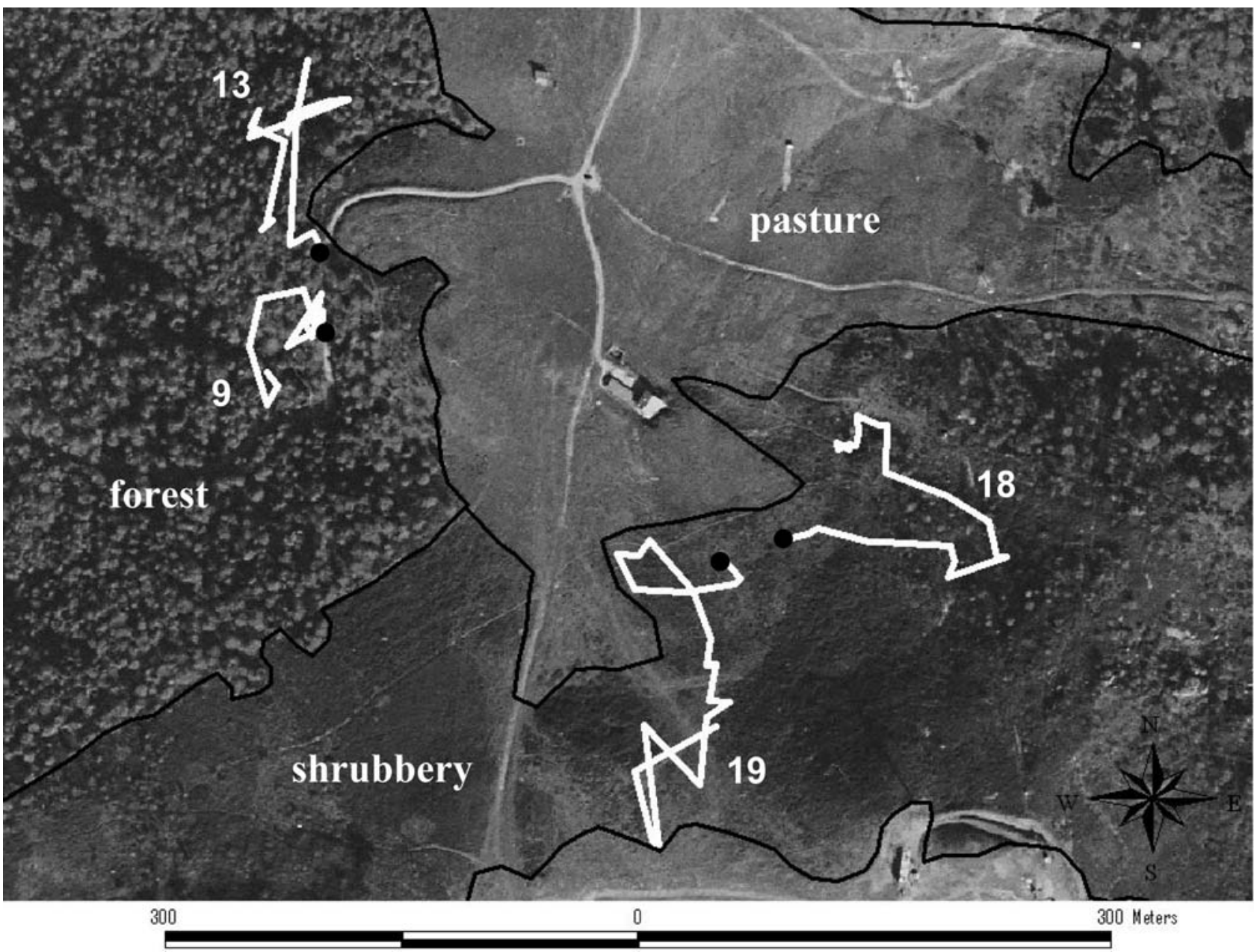

Fig. 4. Movements of four Carabus olympiae males (No. 9 and 13 in beech forest; 18 and 19 in alpen rose shrubbery, see Appendix 1) during a three-week period. The individual No. 19 on two occasions reached the border with the pasture and immediately turned round and went back to the shrubs. Black points represent the site where the beetles were captured and released. 


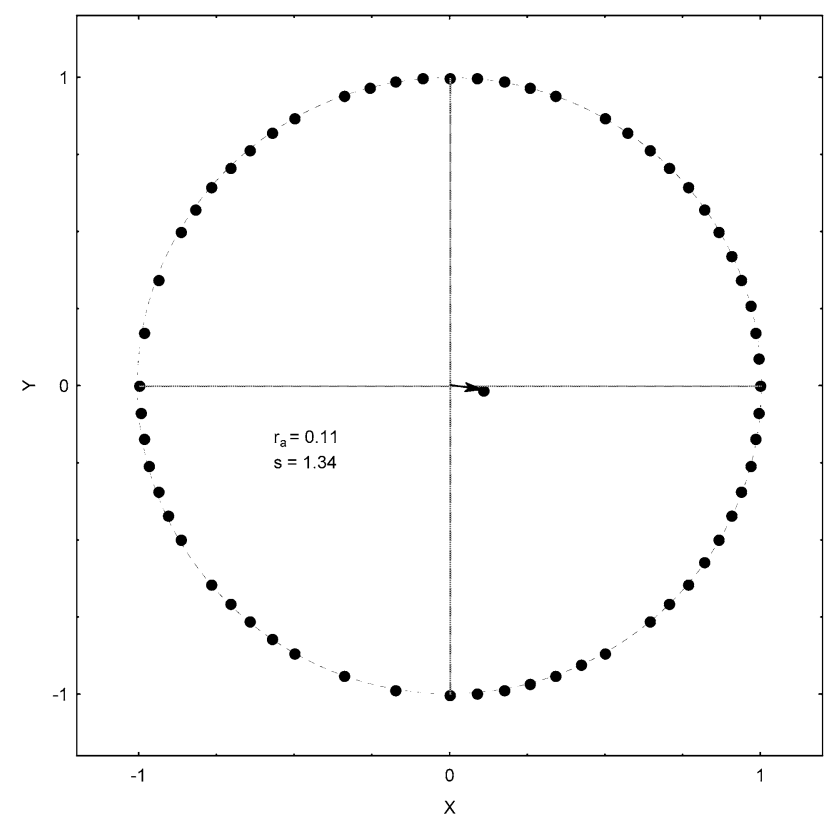

Fig. 5. Circular distribution of the 340 turning angles $\left(\theta_{\mathrm{i}}\right)$ collected (certain points count for more than one angle). The mean vector length $\left(r_{a}\right)$ is equal to 0.11 with a standard deviation (s) of 1.34. Conventionally, angles derived from turning on the right are shown in the lower quadrants, whereas these derived from turning on the left are shown in the upper quadrants.

lected in the shrubbery concerned animals hidden under alpen rose shrubs and 10\% under grass.

No animal left its original habitat. In one occasion a male of a shrubbery reached twice the border with the pasture and immediately turned round and went back to the shrubs (Fig. 4).

Visual inspections of trajectories showed that in both habitats movements had no preferred direction (Fig. 4). The lack of a prevailing walking direction was formally

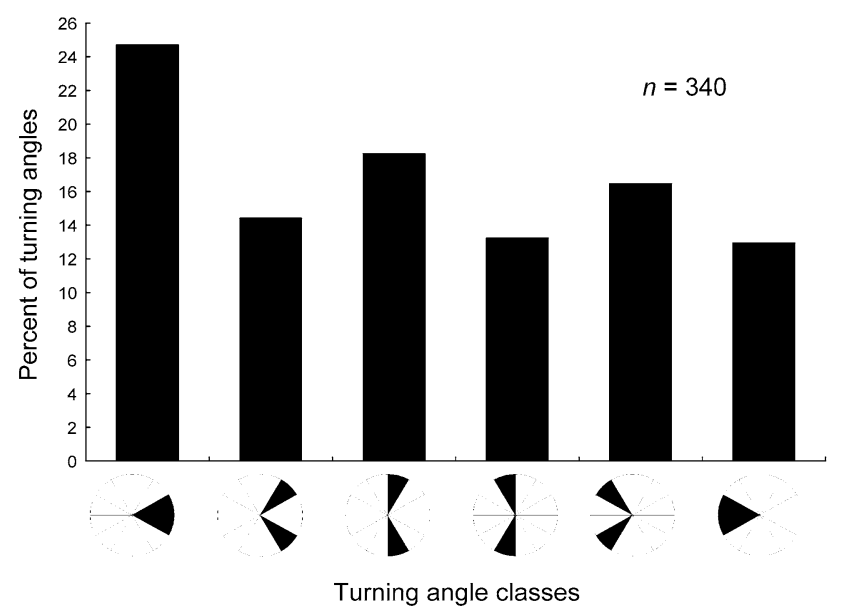

Fig. 6. Frequencies of turning angles classed in six $30^{\circ}$-classes: $0^{\circ} \leq|\theta|<30^{\circ} ; 30^{\circ} \leq|\theta|<60^{\circ} ; 60^{\circ} \leq|\theta|<90^{\circ} ; 90^{\circ} \leq$ $|\theta|<120^{\circ} ; 120^{\circ} \leq|\theta|<150^{\circ} ; 150^{\circ} \leq|\theta|<180^{\circ} ; n=$ number of angles measured. Note that angles are classed according to their measures irrespectively of turning on the right (lower quadrants) or on the left (upper quadrants).

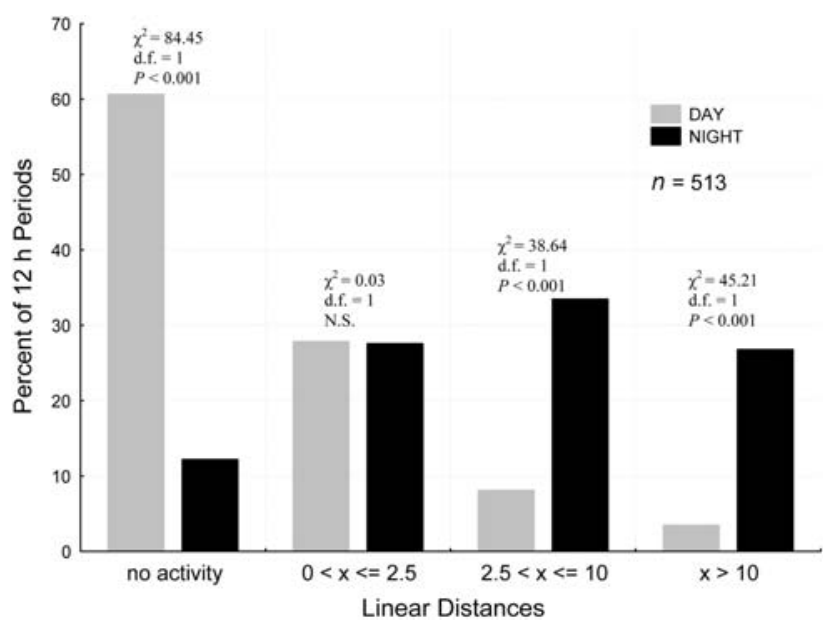

Fig. 7. Linear distances covered by ground beetles during daily (grey bars) and nocturnal (black bars) 12-h bouts. For each distance class differences between observed and expected (assuming individuals were equally active at night and by day) frequencies of bouts were $\chi^{2}$ tested. $n=$ number of linear distances measured.

confirmed by statistics on turning angles. Angles $(n=$ 340) were evenly distributed (Fig. 5) and angular concordance was therefore low $\left(r_{a}=0.11 ; s=1.34\right)$. Even individual angular concordance (computed for each of 21 individuals) were low (average $r_{a}=0.27 ; s=1.20$ ). Angles were classed into six $30^{\circ}$-classes from smaller $\left(0-30^{\circ}\right)$ to larger $\left(150-180^{\circ}\right)$ (Fig. 6). Observed frequencies were significantly different from expected ones (calculated by assuming an even distribution of angles among classes $)\left(\chi^{2}=19.96\right.$; d.f. $\left.=5 ; P=0.001\right)$. However, these differences depend on the relatively higher frequencies of small angles $\left(<30^{\circ}\right)$; when these angles were excluded from the analysis, observed frequencies of the other classes were not significantly different from the expected ones assuming an even distribution among classes $\left(\chi^{2}=\right.$ 4.59; d.f. $=4 ; P=0.33$ ). Mean angular concordation was not significantly different between sexes and habitat types (Table 2).

Individuals were able to walk for several metres per 12-h interval. Distances covered in forest were not significantly different from those covered in shrubbery; males covered longer distances than females $(5.5 \pm 7.3 \mathrm{~m}$ and $2.2 \pm 2.2 \mathrm{~m}$, respectively, Table 2 ).

Radio-tagged individuals were more active at night than by day (Table 2); during most of the diurnal bouts, they did not move or moved for less than $2.5 \mathrm{~m}$, whilst long distances (the maximum linear dispersal range was 77.7 m) were almost exclusively covered at night (Fig. 7).

Paths were more compact (and tortuous) in males than in females, and in beech forest than in alpen rose shrubbery (Table 2 ).

Radio-tagging did not disturb carabids: on several occasions tagged individuals were observed to eat snails or slugs (Arianta arbustorum, Arion and Limax spp.) $(n=3$, Fig. 1) and to copulate with untagged partners $(n=2$, Fig. $1)$. 
TABLE 2. Differences in movement parameters (distance, angular concordation and tortuosity) between sexes (male and female), habitat (beech forest and alpen rose shrubbery) and periods (day and night) tested by three-way (for distances) and two way ANOVA (for angular concordance and tortuosity). Mean \pm SD of distances (in m), angular concordance and tortuosity are given. Interactions between factors were never significant. $\mathrm{P}^{*}<0.05, \mathrm{P} * * *<0.001$.

\begin{tabular}{|c|c|c|c|c|c|c|c|}
\hline \multirow{3}{*}{$\begin{array}{l}\text { Factors } \\
\text { Habitat }\end{array}$} & \multirow{3}{*}{$\begin{array}{l}\text { Categories } \\
\text { Forest } \\
\text { Shrubbery }\end{array}$} & \multicolumn{6}{|c|}{ Parameters } \\
\hline & & \multicolumn{2}{|c|}{ Distances } & \multicolumn{2}{|c|}{ Angular concordance } & \multicolumn{2}{|c|}{ Tortuosity } \\
\hline & & $\begin{array}{l}4.5 \pm 6.3 \\
4.1 \pm 6.1\end{array}$ & $F_{(1,34)}=0.0$ & $\begin{array}{l}0.3 \pm 0.1 \\
0.3 \pm 0.1\end{array}$ & $F_{(1,17)}=0.0$ & $\begin{array}{l}2.8 \pm 1.0 \\
1.8 \pm 0.7\end{array}$ & $F_{(1,17)}=5.5^{*}$ \\
\hline Sex & $\begin{array}{l}\text { Male } \\
\text { Female }\end{array}$ & $\begin{array}{l}5.5 \pm 7.3 \\
2.2 \pm 2.2\end{array}$ & $F_{(1,34)}=5.9^{*}$ & $\begin{array}{l}0.2 \pm 0.1 \\
0.3 \pm 0.2\end{array}$ & $F_{(1,17)}=1.2$ & $\begin{array}{l}2.5 \pm 1.0 \\
1.8 \pm 0.7\end{array}$ & $F_{(1,17)}=5.5^{*}$ \\
\hline Period & $\begin{array}{l}\text { Night } \\
\text { Day }\end{array}$ & $\begin{array}{l}7.5 \pm 7.3 \\
1.0 \pm 1.2\end{array}$ & $F_{(1,34)}=26.0 * * *$ & & & & \\
\hline
\end{tabular}

\section{DISCUSSION}

Ground beetles are more or less specialized predators which play a fundamental role in ground ecosystems (Hance, 1990; Magagula, 2003; Samways, 2005; Öberg \& Ekbom, 2006). Hence, the conservation of endemic species in hotspot areas (like the Alps) is a high priority task both to preserve biodiversity and to ensure local ecosystem functioning. C. olympiae is an example of the steno-endemic and endangered species dwelling in hotspot areas. Despite the need for preserving this species, many aspects of its autecology are virtually unknown.

$C$. olympiae is known to be a relic of a lineage of forest dweller carabids inhabiting sub-tropical forests (widely spread along the southern slopes of the Alps until the late Tertiary) which survived in an area that is a well known Pleistocene refuge for many endemic taxa (Sturani, 1947; Casale \& Vigna Taglianti, 1993). Its habitat selection habit may be considered a relic as well: $C$. olympiae requires environmental conditions that are found in a mountain belt comprised between 1,000 and $1,500 \mathrm{~m}$ a.s.1., with rather high rainfall (more than 1,500 $\mathrm{mm} /$ year), where dense and moist beech forests and shrubs can grow. These conditions are met in the Sessera valley, but not in the adjacent areas, where a true prealpine belt is absent. Close to the investigated area, the landscape changes dramatically, with low hills to the South and high Alpine peaks to the North. Historical factors might therefore explain both present habitat selection pattern and restricted range.

Phenology was assessed through pitfall trapping. The population peaked in July, when most adult individuals were caught; mature larvae appeared from September. This phenological pattern suggests that $C$. olympiae is a spring breeder species without (or with an exceptional) larval dormancy. Previous data suggesting this species peaked in early and late summer, with aestivation in July (Casale et al., 1982), were not confirmed. This mismatch may be due to methods previously used (searching at sight, looking for beetles under stones etc.), which provided incorrect estimates. However, the suggestion that the present phenological pattern is a result of the changes in climate which have been affecting the western Italian Alps during the last few decades (drier and warmer springs, summers and autumns and scarce snow in winter) cannot be excluded.
The modern miniaturization of radiotelemetry tags has provided the opportunity to use radio-tracking for studying movements in large insects (Riecken \& Raths, 1996; Hedin \& Ranius, 2002; Beaudolin-Ollivier et al., 2003; Lorch et al., 2005). Although their weight and dimensional impediment were low, concerns about the effects of tagging on animal behaviour may rise. In a previous paper on movements of the common ground beetle species C. coriaceus, Riecken \& Raths (1996) stated that foraging success was not substantially reduced by micropips. Analogously, observations of tagged individuals while eating molluscs or copulating with untagged partners, suggest radio-tagging did not significantly hinder usual activities in $C$. olympiae. However, a reduction of ranging performances cannot be excluded. In fact, the weight of the tag $(0.3 \mathrm{~g})$ is about $40 \%$ of the average weight of individuals, and the tag fixed on top of the elytra may be a hindrance to the movements across narrow passages (leaf-litter, thick grass, etc.).

On average, individuals moved around with no preferred direction. Trajectories were rather tortuous and local ranges were therefore intensively crossed and explored. This movement patterns perfectly fit the requirements of an "olfactory-tactile" carabid predator that looks for prey by systematically exploring its territory (Brandmayr et al., 2005). Ground beetles of the genus Carabus are known to be nocturnally active (Turin et al., 2003). Radiotelemetric data sustained this habit for C. olympiae as well: individuals did not move or moved for less than three metres (per 12-h interval) by day, whilst they moved for longer distances (up to about $80 \mathrm{~m}$ ) at night.

Males covered longer distances than females and their paths were also more compact than female ones. Males of many insect species are able to detect pheromones produced and emitted by females (Gullan \& Cranston, 1994) and that might also be true for $C$. olympiae. In this framework, we hypothesize that males moved longer and followed paths which were more tortuous in order to diminish the time allocated for the partner search.

Radio-tracking was also useful to identify possible biological co-causes of the permanence of restricted ranges and to single out intimate processes that were responsible for habitat selection patterns. Linear dispersal ranges (within a 12-h period) were rather low (the maximum was 
$77.7 \mathrm{~m}$ ) and suggest a very low dispersal power. It may be assumed that an insect like $C$. olympiae, with independent turning angles, low angular concordance values and negligible differences among turning angles' frequencies moves nearer than an insect that alternates right and left turns and with a significantly greater preponderance of tight angles (Cain, 1989). This, together with the historical factors previously discussed, may concurrently explain why this species, like many other alpine species, after the quaternary glacial period (and once the climatic conditions returned favourable) was unable to re-colonise neighbouring areas and remained confined to a very restricted range.

Occasional observations of radio-tagged individuals from within a shrubbery, which on reaching the border with pasture immediately turned round and went back to the shrubs, confirms that pastures were deliberately avoided. Moreover, it is worth mentioning that some movement parameters (namely distance and angular concordance) measured in beech forests were not significantly different from those measured in alpen rose shrubberies. This strengthens the idea that both habitats are suitable for this species, in complete agreement with pitfall trapping results. However, although shrubberies do not limit linear displacements, the spatial distribution of bushes can slightly constrain trajectories of the radiotagged individuals. Most of the individuals located in shrubberies were hidden under alpen rose shrubs, which probably were used as shelter and protection from predators. Given that paths were less tortuous in shrubbery than in beech forest, it may be assumed that in the former habitat ground beetles were somewhat induced to move from shrub to shrub.

All the above may have relevant implications for the conservation of this species. First of all, any human intervention which causes an enlargement of the present extension of pastures (or any other intervention inducing open habitat, like ski developments) should be limited. Second, forest management (maybe even forests clearing) may be tolerated, on condition that alpen rose shrubbery formations remain or develop after tree-cutting. Once a shrubbery formation has established, it should be preserved. Grazing of sheep and goats, for instance, should be forbidden. These recommendations may be useful to conserve other endemic carabid species of the Sessera valley. In a previous study we pointed out that most species were more abundant in forest and/or shrubberies than in pastures. Only one species (Carabus concolor Fabricius, 1792) presented a reversed habit, being trapped more frequently in pastures than in the other two habitats (Negro et al., 2007).

Last, this study suggests that the best strategy to conserve species with restricted ranges is that of encouraging autecological studies on the endangered populations. In fact, once the habitat selection and movement patterns (and other life-history aspects as well) are known, potential or actual threats may be best faced.

ACKNOWLEDGEMENTS. We thank O. Zegna and Comunità Montana Valle di Mosso for all facilities granted for this study.
The Ministero dell'Ambiente e della Tutela del Territorio provided permission to collect and radio-track individuals. We are also indebted to I. Graci and F. Taverna for field work collaboration. The research was supported by a grant from Comunità Montana Valle di Mosso and from Torino and Sassari Universities (local funds).

\section{REFERENCES}

Arita H.A., Figueroa F., Frisch A., Rodríguez P. \& SantosDel-Prado K. 1997: Geographical range size and the conservation of Mexican mammals. Conserv. Biol. 11: 92-100.

Assmann T. \& JANSSEN J. 1999: The effects of habitat changes on the endangered ground beetle Carabus nitens (Coleoptera: Carabidae). J. Insect Conserv. 3: 107-116.

BAARS M.A. 1979: Patterns of movement of radioactive carabid beetles. Oecologia 44: 125-140.

Batschelet E. 1981: Circular Statistics in Biology. Academic Press, London, $371 \mathrm{pp}$.

Beaudoin-Ollivier L., Bonaccorso F., Aloysius M. \& Kasiki M. 2003: Flight movement of Scapanes australis australis (Boisduval) (Coleoptera: Scarabaeidae: Dynastinae) in Papua New Guinea: a radiotelemetry study. Aust. J. Entomol. 42: 367-372.

Brandmayr P., Zetto T., Pizzolotto R., Casale A. \& Vigna Taglianti A. 2005: I Coleotteri Carabidi per la valutazione ambientale e la conservazione della biodiversità. Manuale operativo, 34, APAT, Roma, 240 pp.

CAIN M.L. 1989: The analysis of angular data in ecological field studies. Ecology 70: 1540-1543.

Casale A., Sturani M. \& Vigna Taglianti A. 1982: Coleoptera Carabidae I. Fauna d'Italia XVIII. Ed. Calderini, Bologna, 499 pp.

Casale A. \& Vigna Taglianti A. 1993: I Coleotteri Carabidi delle Alpi occidentali e centro-occidentali (Coleoptera, Carabidae). Biogeographia (N.S.) 16: 331-399.

Casale A. \& Vigna Taglianti A. 2005: Coleotteri Caraboidei delle Alpi e Prealpi centrali e orientali, e loro significato biogeografico (Coleoptera, Caraboidea). Biogeographia (N.S.) 26: 129-201.

Claussen D.L., Finkler M.S. \& SMith M.M. 1997: Thread trailing of turtles: methods for evaluating spatial movements and pathway structure. Can. J. Zool. 75: 2120-2128.

Collins N.M. \& Thomas J.A. (eds) 1991: The Conservation of Insects and Their Habitats. Academic Press, London, 450 pp.

Fortin M.-J. \& Dale M. 2005: Spatial Analysis, a Guide for Ecologists. Cambridge University Press, Cambridge, 365 pp.

Gerlach J. \& Canning L. 2001: Range contractions in the critically endangered Seychelles terrapins (Pelusios spp.). Oryx 35: 313-321.

Gullan P.J. \& Cranston P.S. 1994: The Insects: An Outline of Entomology. Chapman \& Hall, London, $491 \mathrm{pp}$.

HANCE T. 1990: Relationship between crop types, ground beetle phenology and aphid predation in agroecosystems, In Stork N.E. (ed.): The Role of Ground Beetles in Ecological and Environmental Studies. Intercept, Andover, pp. 55-64.

HEDIN J. \& Ranius T. 2002: Using radio telemetry to study dispersal of the beetle Osmoderma eremita, an inhabitant of tree hollows. Comput. Electron. Agr. 35: 171-180.

Khobrakova L.T. \& Sharova I.K. 2005: Life cycles of ground beetles (Coleoptera, Carabidae) from the mountain taiga and mountain forest-steppe in the eastern Sayan. Biol. Bull. 32: 571-575.

Lorch P.D., Sword G.A., Gwynne D.T. \& Anderson G.L. 2005: Radiotelemetry reveals differences in individual movement 
patterns between outbreak and non-outbreak Mormon cricket populations. Ecol. Entomol. 30: 548-555.

Lövei G., Stringer I.A.N., Devine C.D. \& Cartellieri M. 1997: Harmonic radar - A method using inexpensive tags to study invertebrate movement on land. N. Z. J. Ecol. 21: 187-193.

Magagula C.N. 2003: Changes in carabid beetle diversity within a fragmented agricultural landscape. Afr. J. Ecol. 41: 23-30.

Magura T., KöDÖвÖCZ V. \& TóthmÉRÉSZ B. 2001: Effects of habitat fragmentation on carabids in forest patches. J. Biogeogr. 28: 129-138.

Malausa J.-C., Raviglione M. \& Boggio F. 1983: Il Carabus olympiae Sella dell'Alta Valle Sessera. Pro Natura Biellese, Biella, 113 pp.

MossaKowSKi D. 1979: Evolution of habitat preference illustrated by the phylogeny of Chrysocarabus (Coleoptera, Carabidae). In Den Boer P.J., Thiele H.U. \& Weber F. (eds): On the Evolution of Behaviour in Carabid Beetles. Veenman \& Zonen, Wageningen, pp. 103-111.

Negro M., Casale A., Migliore L., Palestrini C. \& Rolando A. 2007: The effect of small-scale anthropogenic habitat heterogeneity on assemblages of macro-carabids (Coleoptera, Caraboidea) endemic to the Alps. Biodivers. Conserv. 16: 3919-3932.

Niemelä J., Haila Y., Halme E., Pajunen T. \& Punttila P. 1992: Small-scale heterogeneity in the spatial distribution of carabid beetles in the southern Finnish taiga. J. Biogeogr. 19 173-181.

Niemelä J., Kotze D.J., Venn S., Penev L., Stoyanov I., Spence J., Hartley D. \& DE OcA E.M. 2002: Carabid beetle assemblages (Coleoptera, Carabidae) across urban-rural gradients: an international comparison. Landscape Ecol. 17: 387-401.
ÖвеRG S. \& Еквом B. 2006: Recolonisation and distribution of spiders and carabids in cereal fields after spring sowing. Ann. Appl. Biol. 149: 203-211.

O’Neal M.E., Landis D.A., Rothwell E., Kempel L. \& ReinHARD D. 2004: Tracking insects with harmonic radar: a case study. Am. Entomol. 50: 212-218.

PiPeR R.W. \& Compton S.G. 2002: A novel technique for relocating concealed insects. Ecol. Entomol. 27: 251-253.

RieCKEN U. \& Raths U. 1996: Use of radio telemetry for studying dispersal and habitat use of Carabus coriaceus L. Ann. Zool. Fenn. 33: 109-116.

Samways M.J. 2005: Insect Diversity Conservation. Cambridge University Press, Cambridge, 342 pp.

SoKal R.R. \& Rohlf F.J. 1995: Biometry: The Principles and Practice of Statistics in Biological Research. 3rd ed. W. H. Freeman, New York, 887 pp.

Sota T. \& Ishikawa R. 2004: Phylogeny and life-history evolution in Carabus (subtribe Carabina: Coleoptera, Carabidae) based on sequences of two nuclear genes. Biol. J. Linn. Soc. 81: 135-149.

StURANi M. 1947: Notizie ecologiche ed etologiche sul Carabus olympiae Sella (Coleoptera: Carabidae). Boll. Ist. Entomol. Univ. Bologna 16: 23-84.

Turin H., Penev L. \& Casale A. (eds) 2003: The Genus Carabus in Europe - A Synthesis. Pensoft, Sofia, 512 pp.

Upton G.J.G. \& Fingleton B. 1989: Spatial Data Analysis by Example. Vol. II. Categorical and Directional Data. Wiley, New York, 416 pp.

ZAR J.H. 1999: Biostatistical Analysis. 4th ed. Prentice Hall, Englewood Cliffs, New Jersey, 718 pp.

Received May 22, 2007; revised and accepted September 3, 2007 